ON November 1 a Stenographic Exhibition was opened in a room of the Pedagogic Museum of the College, Rome. Stenography at the present day occupies a very important part in the requirements of public life, and we believe the effort to encourage its study by a public exhibition will lead to useful results. On the walls of the room were a list of the Italian towns that had a school or society for stenograpky. The only method followed is that of Gabelsberg-Noe. On a table in the centre of the room were stenographic attempts of every kind, from large plates for elementary study to the smallest and most minute works. In one case, Dante's "Divine Comedy" was copied out into a book of Lilliputian dimensions. On a post-card one stenographer had written 3,660 words. The committee who arranged the exhibition wish to reproduce on the historical wax tablet the stenographic marks with which Tiro wrote the speeches of Cicero.

ON Noyember 2 took place the opening ceremony of the scholastic year of the University of Rome. Prof. Scalzi read a critico-historical exposition of a collection of surgical apparatus belonging to lithotomists and oculists of the sixteenth and eighteenth centuries, which he found among families of the province of Umbria. Prof. Scalzi gave some very interesting details, showing that these instruments were invented in Italy, and not by foreigners, as has been supposed. He showed also that the study of the original instruments was of great interest in connection with the history of the progress of the surgical art. On two tables were arranged eighty instruments which had belonged to surgeons of Novicia and Delle Preci in Umbria. Many of these instruments, it was interesting to observe, resembled those found at Pompeii and others found at Ravenna.

A REPORT by Mr. Frank Buckland, on the fisheries of Norfolk, recently issued, states as a remarkable fact that large numbers of sea trout are annually caught off the coasts of that county, though the rivers which flow through it are naturally incapable of producing Salmonida. The fish thus caught are visitors from the salmon rivers in the north, viz., the Tyne, the Tees, the Coquet, and the Tweed. The object of this visit to the coasts of Norfolk and Suffolk is to find food, which exists in abundance in the shape of the spawn and fry of the many varieties of fish which abound in those waters. The report contains much interesting matter relative to the crab, lobster, and other sea-coast fisheries, and to the fisheries in the fresh-waters of Norfolk and Suffolk.

THE Comptes Rendus for October 4 last contains a paper on the interpretation of the sphygmograph trace, by $\mathrm{M}$. Bouillaud. The author gives reasons, which we think peculiarly unsatisfactory, in favour of the sphygmograph trace--a curve now fairly understood-supporting an assumption of his that each cardiac revolution consists of two periods of action and two of repose, instead of one systole and its associated secondary consequences,

OUR readers will find, in the current number of the $\mathrm{Tb}$ is a short account of the late veteran Swedish ornithologist, Carl J. Sundevall, whose excellent investigations, especially with reference to the Passerine birds, have done much towards the development of sound classificational principles.

We would direct the special attention of our zoological and geological readers to a paper by Prof. Owen in the current zumber of the Quarterly Fournal of the Geological Society, on a fussil Sirerian animal from Jamaica, previously described by him, and named Prorastomus sirenoides. In this animal the premaxilla of eacli side gives indications of having supported three not large teeth, at the same time that there were eight teeth of the molar series above and below, on each side. The species was considerably smaller than the Manatee; the skull and atlas vertebra are the only parts known; in conjunction with
Felsinotherium forrestii it fills an important gap in our knowledge of the pedigree of the Sirenia.

The Geographical Magazine for December contains a paper of great value on the Amú Darya region, by N. P. Barbot de Maruz, who in the summer of 1874 made a journey from Fort Alexandrovski, in the Caspian, to the foot of the Thian-shan. He describes the principal geological features observed along the route, and promises a full report of his researches when he has been able to arrange his abundant materials. Another paper, by Mr. Ravenstein, describes Mr. Stanley's recent discoveries, and is illustrated by two good maps, one of the Victoria Nyanza, principally according to Mr. Stanley, and another of the regions of the Upper Nile, embodying the results of the explorations of Burton, Speke, Grant, Stanley, Baker, Long, and others.

PARTS IO, II, and 12 (in one), of the well-conducted Italian geographical journal, Cosmos, are to hand. The following are the principal papers :-A letter from F. Giordano, giving sorne account of the condition of New Guinea, in reference to a proposal to make use of some part of it as an Italian penal settlement. Another letter, from Dr. Beccari, describes some results of his investigations into Papuan ethnology. The first of a series of papers on Arctic Geography gives the results of recent Arctic exploration in the Baffin's Bay and Spitzbergen directions.

We learn from the American Naturalist that State Associa. tions of Archæology have been formed in Indiana and Tennessee, similar to that already existing in the State of Ohio. Their field of work is most extensive and important.

ON Thursday, November 26 , at 6.35 P.M., an earthquake shock was distinctly felt at Lyons. The commotion, which travelled northwards, lasted from fifteen to twenty seconds.

A sHock of earthquake was felt at Naples on Dec. 6, and also throughout the provinces of the Basilicata, Terra di Lavoro, and Salerno.

THe additions to the Zoological Society's Garcens during the past week include a male Prince Alfred's Deer (Cervus alfredi), born in the Gardens; a Green Monkey (Cercopithecus callitrichus) from West Africa, presented by Mr. C. F. Wood; a Macaque Monkey (Macacus cynomolgus) from India, presented by Miss Kate Symonds; two Alligators (Alligator mississippi. ensis) from North America, deposited; twenty-nine Basse ( $L a b$ rax lupus); a Grey Mullet (Mugil capito), and six Cottus (Cottus bubalis) from home seas, purchased.

\section{THE DIFFERENCE OF THERMAL ENERGY TRANSMITTED TO THE EARTH BY RADI- ATION FROM DIFFERENT PARTS OF THE SOLAR SURFACE}

THE observations relating to the temperature of the polar regions, referred to in the article (vol. xii. p. 5i7), at first led to the supposition that the rays projected from the north pole of the sun transmit a perceptibly greater energy to the actinometers than the rays from the opposite pole. Subsequent observation; having positively established the fact that the polar and equatorial zones transmit equal intensities, it became evident that some other cause than difference of temperature within the polar regions influenced the actinometers. The only valid reason that could be assigned in explanation of the anomaly being the considerable angle subtended, and the consequent difference of zenith distance of the opposite poles of the sun, my table of maximum solar intensity for given zenith distances (prepared from data collected during a series of years) was consulted, in order to ascertain the influence of zenith distance. The observations indicating a higher temperature at the north pole, it should be mentioned, had been made while the sun's zenith distance ranged between $32^{\circ}$ and $33^{\circ}$ at noon. Now the table referred to shows that there is a difference of radiant intensity of $63^{\circ} .63-$ $63^{\circ} 40=0^{\circ} \cdot 23 \mathrm{~F}$. between the stated zenith distances. The mean angle subtended by the sun being fully thixty-two minutes, 
it will thus be seen that, owing to the absorptive power of the terrestrial atmosphere, the radiant intensities transmitted from the opposite poles of the luminary differ considerably. The magnitude of this difference, adequate to explain the discrepancy under consideration, need not excite surprise if we consider that thirty-two minutes of zenith distance involves an additional depth of more than half a mile of atmosphere to be penetrated by the rays projected towards the actinometer from the south pole of the sun. The foregoing facts show the necessity of taking the difference of zenith distance between the opposite poles into account in making exact observations of the sun's polar temperature, especially at the lower altitudes where the secant of the zenith distance increases rapidly.

Regarding the calorific energy of the radiation emanating from the border of the sun, I deem it proper to present the following brief statement. Several observations during the early part of the investigation pointed to the fact that increased energy is transmitted to the actinometers by radiation from the sun's border. Again, considerable irregularity was observed in the progressive diminution of the force of radiation towards the circumference of the solar disc. It was shown in the preceding article (vol. xii, p. 520) that the radiation from the border zone, $1^{\prime} 42^{\prime \prime}$ wide, occupying one-fifth of the area of the solar disc, transmits 0.638 of the intensity transmitted from an equal area at the centre of the disc. Of course it will be supposed that the rate of the diminution of intensity within the zone thus ascercained is much greater near the border of the photosphere than at the middle of the zone. Such, however, is by no means the case, notwithstanding the assumption of phycisists that the heat transmitted by radiation from the border is very feeble. In order to test the truth of the indications referred to showing considerable radiant energy at the border of the photosphere, a very careful investigation was made, Sept. 9, 1875, by means of screens excluding the rays from the solar disc, as shown in Figs, i 2 and 13. The diameter of the screen represented in Fig. 12 being I 54.06 millimetres, covered nine-tenths of the area of the disc; while the screen shown in Fig. 13 , being 145.25 millimetres, covered four.fifths of the disc. It will be well to mention that the dimensions of the screens referred to correspond with the angle subtended by the sun when the earth is in aphelion. Accordingly the distance between the actinometers and the screens was adjusted previous to the observation, viz. shortenea, in order to compensate for the increase of the angle subtended by the sun. Agreeable to the stated dimensions of the screens, it will be found that the zone represented in Fig. 13 is $I^{\prime} 42^{\prime \prime}$, while the zone in Fig. I2 is $49^{\prime \prime} \cdot 6$. The mean width of the latter is consequently situated only $24^{\prime \prime} \cdot 3$ from the border of the photosphere.

The following table shows the intensities transmitted to the

actinometers from the zones represented in Fiss. $r_{2}$ and $r_{3}:-$

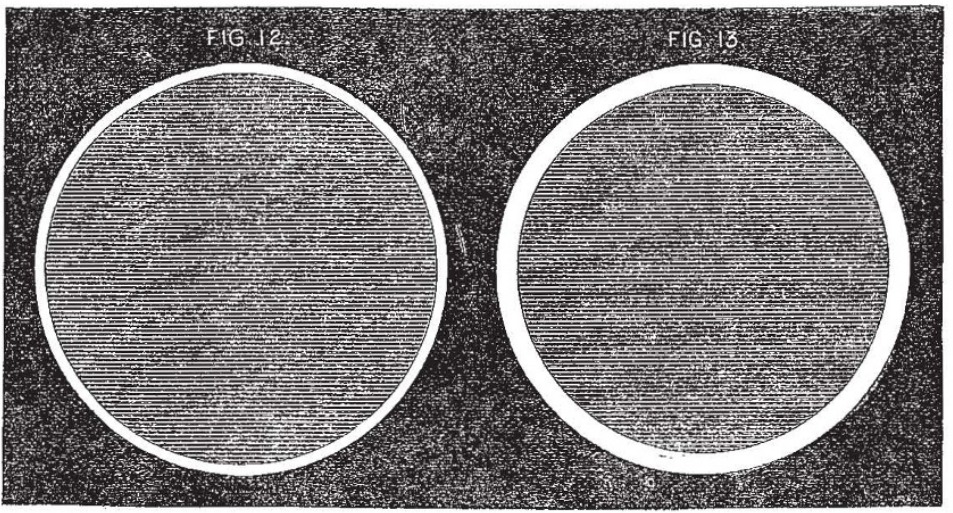

$$
\begin{aligned}
& \text { Inte of aficunce. } \\
& x \cdot 333=0.662 \\
& 2011 \\
& \frac{x \cdot 47}{2248}=0.654 \\
& \times 553=0.652 \\
& 2.425= \\
& 1665 \\
& 2.485=0.670 \\
& \text { Mean }=0.660
\end{aligned}
$$

The rate of difference inserted in the last column, it will be noticed, is not quite so consistent as in the table contained in the previous article recording the observations made Aug. 25. The

FI:

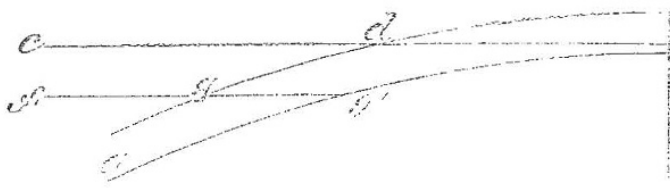

discrepalicy is, however, not material, the difference between the lowest and the mean rate being $0^{\circ} 008$. It wiil be seen on inspecting the registered intensities, that the border zone represented in Fig. I2, whose area is only one-half of the area of the zone in Fig. 13, transmits 0.660 of the intensity of the latter. This at first sight indicates an extremely disproportionate transmission of heat from the narrow border zone; but it should be considered that the inflected radiation imparts relatively more heat to the actinometer exposed to the radiation from the narrow zone than from the wide zone. It will be readily understood that since the inflection of the calorific rays is $I 4^{\prime \prime} \cdot 7$ (see preceding article, page 519), the first-mentioned actinometer receives radiant heat from $14^{\prime} \cdot 7+49^{\prime} \cdot 6=64^{\prime \prime} \cdot 3$; while the actinometer exposed to the radiation from the wide zone receives heat from $\mathrm{I}^{\prime} 42^{\prime \prime}+14^{\prime \prime} \cdot 7=116^{\prime \prime} \cdot \%$. Consequently, the radiant heat emanating from the narrow zone will be $\frac{64^{\prime \prime} \cdot 3}{116^{11} \cdot 7}=$ 0.55 I of that transmitted from the wide zone, hence somewhat more than one-half. Our investigation therefore proves that the radiant heat transmitted from the narrow border zone represented in Fig. 12 is $0.660-0.55 \mathrm{I}=0.109$ more intense than that transmitted from the zone represented in Fig. ${ }_{3} 3$, although the mean distance of the latter is twice as far from the border of the Fhotosphere as the mean distance of the former. The singular fact thus revealed can only be accounted for by supposing that internal radiation is not incompatible with the constituiton of the photosphere, and by adopting Lockyer's views expressed in the Serate House at Cambridge, 187 I, that "the photosphere must be a something suspended in the solar atmosphere." Let $a b$, Fig. 14, represent a section of the "suspended" photosphere, and $d c, g f$, rays projected towards the earth. Agreeable to the conditions mentioned, and in view of the fact that the force of radiation from incandescent gases presenting equal areas, varies nearly as their depth, we are warranted in concluding that since the depth $d d^{\prime}$ is greater than $g g^{\prime}$, the radiant heat transmitted from the pholosphere by the ray $d c$ will be greater than that transmi:ted by the ray $g f$. It should be observed that the energy transmitted towards the earth by $d c$ suffers a greater diminution than the energy transmitted by of $f$ in consequence of the greater depth of the solar atmosphere penetrated. Hence the augmented energy established by our investigation, does not show the full amount of the increase of radiant heat transmitted from the border of the sun.

\section{J. ERICSSON}

